\title{
Toward a Uniform Analysis of Short Answers and Gapping
}

\author{
Ingo Reich \\ University of Tübingen
}

\section{Introduction}

In the literature on gapping it is common practice to introduce a gapped sentence on the background of a multiple $w h$-question, the main reason probably being to facilitate parsing of the relevant example. The grammaticality of the gapped sentences in (1), for example, becomes immediately obvious, in case they are taken to answer the questions in (2), respectively (see Steedman, 1990).

(1) a. Harry went to London, and Barry Detroit.

b. Harry will give a bone to a dog, and Barry a flower to a policemen.

c. Harry claimed that hedgehogs eat mushrooms, and Barry frogs.

(2) a. Which city did each man go to?

b. Which man will give what to whom?

c. What did each man claim that hedgehogs eat?

(3) a. Harry London, and Barry Detroit.

b. Harry a bone to a dog, and Barry a flower to a policemen.

c. Harry mushrooms, and Barry dogs.

As Steedman (1990, 248) puts it "[...] even the most basic gapped sentence like Fred ate bread, and Harry, bananas is only really felicitous in contexts which support (or accommodate) the presupposition that the topic under discussion is Who ate what?." In this paper, I want to argue that Steedman's remark hits the spot: given an adequate analysis of short answers, this analyis can be straightforwardly generalized to gapping within any model of discourse that is based on the assumption that discourse is structured by explicit or implicit wh-questions (e.g. Roberts, 1996; Büring, 2003). This, of course, is essentially equivalent to saying that the only difference between short answers and gapping boils down to the following: whereas in case of short answers the relevant $w$ h-question is always present explicitly, this question typically needs to be reconstructed on the basis of the information structure of the initial conjunct in case of gapping.

To substantiate the claim of a uniform analysis of short answers and gapping, I will first point at some well-known, but nevertheless suggestive commonalities between short answers and gapping. I will then sketch Rooth's (1992) theory on question/answer congruence, and show that the constraint Rooth imposes on congruent sentential answers turns out to be an empirically adequate condition for ellipsis in short answers, in fact a more adequate condition than Merchant's (2001) notion of e-Givenness. In a second step, I will generalize the short answer analysis to gapping along the lines suggested by Steedman's quote. Actually, I will present two versions of the uniform approach: one version within alternative semantics, the other one within Schwarzschild's (1999) theory on F-marking and accent placement. The paper closes with a discussion of some interesting implications of a uniform approach to short answers and gapping.

\footnotetext{
* I'd like to thank audiences at SCEF 2003 (Tübingen), ISAG 2004 (Tübingen), LaMa 2004 (Stuttgart), and TLS 8 (Austin, Texas) for helpful discussion. Special thanks go to Kai von Fintel, Danny Fox, Irene Heim, Klaus von Heusinger, Manfred Krifka, Jason Merchant, Kerstin Schwabe, Jürgen Pafel, Marga Reis, and Susanne Winkler. This work has been supported by grant RE 1663/1-1 of the German Science Foundation (DFG).
} 


\section{Some (Very) Suggestive Commonalities}

Non-Constituent Deletion As is already obvious from the examples cited above, both short answers and gapping are prima facie cases of non-constituent deletion. Although well-known, this common property is nevertheless quite remarkable: assuming that stripping is a subcase of gapping, right node raising is probably the only other deletion process that does not respect constituency.

Finite First Condition But whereas in case of right node raising the finite verb is never affected by the deletion process, it is always affected in short answers and gapping, see (4).

(4) a. Which man gave a book to which woman? *Harry gave to Sue, ...

b. *Harry gave a book to Sue, and Bill gave to Mary.

Locality Conditions I Third, short answers and gapping are subject to quite similar locality constraints. Consider German, for example. Neither in the case of short answers nor in the case of gapping is it possible to separate the ellipsis site from its antecedent by embedding the former under a predicate that only subcategorizes for verb-final sentences, see (5):

(5) a. Wer hat wen eingeladen? *Ich weiß, (dass) Harry Sue eingeladen hat, ... Who has who invited? *I know, (that) Harry Sue

b. *Harry hat Sue eingeladen, und ich weiß, (dass) Bill Mary *Harry has Sue invited, and I know, (that) Harry Sue

It is possible, however, if the relevant predicate also subcategorizes for V2-sentences:

(6) a. Wer hat wen eingeladen? Ich glaube, Harry Sue ... Who has who invited? I believe, Harry has Sue invited,

b. Harry hat Sue eingeladen, und ich glaube, Bill hat Mary eingeladen Harry has Sue invited, and I believe, Harry has Sue

Major Constituent Constraint Fourth, both short answers and gapping obey Hankamer's (1979) 'Major Constituent Constraint,' which, roughly speaking, states that a remnant is only well-formed if it is (a nonverbal constituent) immediately dominated by the root-clause or by some node of its verbal projection:

(7) a. Did John invite the semanticist from MIT or the semanticist from Amsterdam?

b. * from MIT.

*John invited the semanticist from MIT and Bill from Amsterdam.

Island Sensitivity Finally — and apparently related to the previous property — short answers and gapping pattern alike with respect to islands as illustrated in (9) and (10) for so-called adjunct islands:

(9) Who will be offended if we invite which colleague?

a. John will be offended if we invite Bill, ...

b. ?John if we invite Bill, ...

c. ?*John Bill, ...

(10) John will be offended if we invite Bill, and

a. Jane will be offended if we invite Martha.

b. ?Jane if we invite Martha.

c. ?*Jane, Martha. 


\section{A 'Topical' Account within Alternative Semantics}

Taken all together, these facts constitute, I think, sufficient empirical evidence for the assumption that a uniform approach to short answers and gapping is in fact desirable and promising. In the following, I will present a proposal to this effect. This will be done in two steps. First, I will illustrate on the basis of short answers that a variant of Rooth's condition on congruent sentential answers is in fact already an adequate condition on ellipsis in question answer sequences (and gapping). In a second step, this condition will be generalized to gapping by linking gapping to implicit questions or ‘questions under discussion' (QUDs).

\subsection{Deriving Short Answers from Congruent Sentential Answers}

What is a good answer to a given question? Consider (11) for illustration. Whereas (11b) is a perfect answer to the question in (11a), the not so perfect 'answers' in (11c) and (11d) show that there are important wellformedness constraints on answers concerning both form and meaning: (11c) is not a well-formed answer, because the grammatical role of the minimally focused constituent John in the answer (subject), does not match the grammatical role of the corresponding $w h$-phrase in the question (object); (11d), on the other hand, is out, because what we know about the linguist Noam Chomsky is definitely in conflict with the sortal restriction student carried by the wh-phrase in (11a).

(11) a. Which student did John invite $t$ ?

b. John invited $[\mathrm{SUE}]_{\mathrm{F}}$.

c. $*[\mathrm{SUE}]_{\mathrm{F}}$ invited John.

d. \#John invited [NOAM CHOMSKY $]_{\mathrm{F}}$.

(12) a. $\llbracket(11 \mathrm{a}) \rrbracket=\{p ; \exists x, x$ a student $\& p=$ that John invited $x\}$

b. $\llbracket(11 \mathrm{~b}) \rrbracket_{\mathrm{F}}=\left\{p ; \exists x, x \in D_{e} \& p=\right.$ that John invited $\left.x\right\}$

c. $\llbracket(11 \mathrm{c}) \rrbracket_{\mathrm{F}}=\left\{p ; \exists x, x \in D_{e} \& p=\right.$ that $x$ invited John $\}$

Given a Hamblin-style analysis for $w h$-interrogatives, both constraints can be dealt with within Rooth's (1992) theory on question/answer congruence. According to Hamblin a question like (11a) denotes the set of its possible answers, i.e., the set of propositions of the kind that John invited $x, x$ being some arbitrary student, see (12a). According to Rooth the focus/background structure of a sentence is interpreted on a second layer of interpretation - the focus value $\llbracket \alpha \rrbracket_{F}$ of an expression $\alpha$, where foci are treated more or less like pronominal in situ $w h$-phrases in Hamblin's approach (which are, however, not subject to any sortal restrictions, apart from type-identity). In case of (11b) the focus value we derive is the set of propositions of the form that John invited $x$ - see (12b); in case of (11c) we end up with the set of propositions of the form that $x$ invited John — see (12c) (for details the reader is referred to Rooth, 1992). Though all three sets of propositions share exactly one proposition — namely that John invited John — there is one important difference: whereas the denotation of the question in (11a) is a subset of the focus value of (11b), this is not true in case of (11c). As a consequence, the formal aspect of the answerhood relation can be captured by a subset relation: the focus value of a congruent (i.e., well-formed with respect to formal properties) answer A needs to be a superset of the denotation of the question Q it is meant to answer, see the F-Answer constraint in (13b). The content-related restriction excluding (11d) as a well-formed answer to (11a) apparently reduces to the element relation, see the C-Answer constraint in (13a).

(13) $Q /$ A congruence within alternative semantics

a. C-Answer: $\llbracket A \rrbracket \in \llbracket Q \rrbracket$.

b. F-Answer: $\llbracket Q \rrbracket \subseteq \llbracket A \rrbracket_{\mathrm{F}}$ (and $\left|\llbracket Q \rrbracket \cap \llbracket A \rrbracket_{\mathrm{F}}\right| \geq 2$ ).

On the level of logical form, the F-Answer condition is formally implemented by the so-called squiggleoperator $\sim$ which adjoins to the answer's $\mathrm{CP}$ and introduces a context variable $\Gamma$ that picks up the denotation of the preceding question via coindexing: 
(14) a. [Which professor did John invite $t$ ? $]_{1}$

b. [John invited [Noam Chomsky $\left.]_{\mathrm{F}}\right] \sim \Gamma_{1}$.

To avoid cases of so-called 'overfocusing' in sentential answers, a condition like Schwarzschild's (1999) constraint AvoidF — avoid unnecessary focus marking — needs to be assumed (see e.g. the discussion in Krifka, 2001; Büring, 2002). However, as examples like the one in (15) show, there is a natural limit to the application of this constraint within $\mathrm{Q} / \mathrm{A}$ sequences:

(15) (A: John drove Mary's red conVERtible.)

a. B: What did he drive before?

b. A: Before, he drove [Mary's $[\text { BLUE }]_{F}$ convertible $]_{F}$.

AvoidF mustn't delete F-markers that correspond to $w h$-phrases in the preceding $w h$-question -as a consequence, F-Answer needs to be ranked higher than AvoidF: F-Answer » AvoidF (see Reich, 2002b).

Now let's pose the following question: Is the F-Answer condition on congruent sentential answers already an adequate condition for ellipsis in Q/A sequences? Suppose for the moment it is, then we can define ellipsis at PF as follows: delete everything unless it is (part of) an F-marked constituent, see (16).

(16) PF-deletion

a. F-markers are upper bounds to PF-deletion.

b. Maximize PF-deletion.

(short answers, gapping)

It is easy to see that this accounts for both the Q/A sequence in (17) and the one in (18):

(17) a. [Which professor did John invite $t$ ? $]_{1}$

b. $\left.[\text { Noam Chomsky }]_{\mathrm{F}}\right] \sim \Gamma_{1}$.

(18) [A: John drove Mary's red conVERtible.]

a. B: [What did he drive before? $]_{1}$

b. $\left.\left[\text { Mary's }[\mathrm{BLUE}]_{\mathrm{F}} \text { convertible }\right]_{\mathrm{F}}\right] \sim \Gamma_{1}$.

Moreover, if it can be shown that the subset condition is in fact an adequate condition for ellipsis in Q/A sequences, and if this condition can be generalized to gapping, then we seem to get gapping for free:

(19) JOHN likes MARY and $\left[\left[[\mathrm{MARY}]_{\mathrm{F}}\right.\right.$ tikes $\left.\left.[\mathrm{JOHN}]_{\mathrm{F}}\right] \sim \Gamma\right]$.

\subsection{The Subset Condition as a Semantic Condition on Ellipsis}

So let's first try to answer the question of whether the condition F-Answer on congruent sentential answers is indeed an adequate condition on ellipsis in Q/A sequences and/or gapping. To show this, I will follow a somewhat indirect strategy: based on Schwarzschild's (1999) notion of Givenness, Merchant (2001) develops the notion of e-Givenness which he argues at length is a sufficient condition on ellipsis (on sluicing and VP ellipsis, to be precise). What I want to show in the following is that Rooth's F-Answer condition (or, similarly, Rooth's notion of symmetric contrast) is in fact the stronger notion of the two, i.e., if e-Givenness is a sufficient condition on ellipsis, then Rooth's subset conditon certainly is, too. To keep things as simple as possible (and types uniform), I will illustrate this result with gapping.

What exactly is e-Givenness? In a nutshell, e-Givenness is a two-part condition based on Schwarzschild's (1999) notion of Givenness:

(20) e-Given An expression E counts as e-given

iff $\mathrm{E}$ has a salient antecedent $\mathrm{A}$ and, modulo existential type shifting,

a. A is given relative to $\mathrm{E}$, and

b. $\mathrm{E}$ is given relative to $\mathrm{A}$. 
Since given is an entailment relation modulo focus marking between two expressions A and E, see (21),

(21) Given An expression E counts as given iff $\mathrm{E}$ has a salient antecedent $\mathrm{A}$ and, modulo existential type shifting, A entails the F-closure of $\mathrm{E}$ (where the F-closure of $\mathrm{E}-\mathrm{FClo}(\mathrm{E})$ - is the result of replacing F-marked expressions in $\mathrm{E}$ with variables and existentially closing the result).

e-Givenness encodes a semantic equivalence relation modulo focus marking. The same is true of Rooth's notion of symmetric contrast, which is implemented by a somewhat different version of the squiggleoperator ' $\sim$ ': the second conjunct in (22a) contrasts with the first conjunct, if the first conjunct's denotation is an element of the focus value of the second conjunct, and vice versa, see (22b).

(22) a. $\left[\left[[\mathrm{JOHN}]_{\mathrm{F}} \text { likes }[\mathrm{MARY}]_{\mathrm{F}}\right] \sim \gamma_{2}\right]_{1}$ and $\left[\left[[\mathrm{BILL}]_{\mathrm{F}} \text { likes }[\mathrm{SUE}]_{\mathrm{F}}\right] \sim \gamma_{1}\right]_{2}$.

b. where $\alpha \sim \gamma$ presupposes that $\llbracket \gamma \rrbracket \in \llbracket \alpha \rrbracket_{\mathrm{F}}$

As long as both conjuncts show parallel focus structure, Merchant's notion of e-Givenness and Rooth's notion of symmetric contrast are in fact equivalent. It should be noted, however, that neither e-Givenness nor symmetric contrast necessarily imply parallel focus structure. Symmetric contrast, for example, also allows for the following situation as long as $\beta$ is semantically identical to $\alpha$ : $\beta$ is not contained in an F-marked constituent in the second conjunct, the corresponding expression $\alpha$ in the first conjunct however is F-marked or is contained in an F-marked constituent. (23) illustrates this situation with $\alpha=\beta=$ likes.

$$
\left[\left[[\mathrm{JOHN}]_{\mathrm{F}}[\text { likes MARY }]_{\mathrm{F}}\right] \sim \gamma_{2}\right]_{1} \text { and }\left[\left[[\mathrm{BILL}]_{\mathrm{F}} \text { likes }[\mathrm{SUE}]_{\mathrm{F}}\right] \sim \gamma_{1}\right]_{2} \text {. }
$$

But if $\beta$ is not semantically equivalent to $\alpha$, then Rooth's notion of symmetric contrast is violated. (24) illustrates this with $\alpha=$ to call someone a Republican and $\beta=$ to insult someone. (The proposition that Mary insulted John is an element of the focus value of the first conjunct, but the proposition that John called Mary a Republican is definitely not an element of the focus value of the second conjunct.)

$$
\left[\left[[\mathrm{JOHN}]_{\mathrm{F}}[\text { called Mary a RePUBlican }]_{\mathrm{F}}\right] \sim \gamma_{2}\right]_{1} \text {, and then }\left[\left[[\mathrm{MARY}]_{\mathrm{F}} \text { insulted }[\mathrm{John}]_{\mathrm{F}}\right] \sim \gamma_{1}\right]_{2} \text {. }
$$

Both (23) and (24) exemplify the important phenomenon of 'deaccentuation'. The crucial point here is the following: whereas (24) is not licensed by symmetric contrast, it is licensed by e-Givenness. (The second conjunct is given relative to the first conjunct, since the proposition that John called Mary a Republican entails —-mediated by pragmatic reasoning - that someone insulted someone; and the first conjunct is given relative to the second conjunct, since the proposition that Mary insulted John entails the F-closure of the first conjunct which is simply the trivial proposition $p \vee \neg p$.) This shows two things:

(i) symmetric contrast is the stronger notion, and

(ii) e-Givenness is in general too weak as an adequate condition on ellipsis.

If we finally take into account that 'deaccentuation' is essentially an asymmetric notion - expressions in the first conjunct deaccenting expressions in the second conjunct, and not vice versa- then symmetric contrast is basically equivalent to the subset condition stated in (25b) and illustrated with (25a): the focus value of the second conjunct is required to be a subset of the focus value of the first conjunct.

(25) a. $\left[[\mathrm{JOHN}]_{\mathrm{F}}[\text { likes MARY }]_{\mathrm{F}}\right]_{1}$ and $\left[\left[[\mathrm{BILL}]_{\mathrm{F}}\right.\right.$ ites $\left.\left.[\mathrm{SUE}]_{\mathrm{F}}\right] \sim \Gamma_{1}\right]$.

b. $\alpha \sim \Gamma$ presupposes that $\llbracket \alpha \rrbracket_{\mathrm{F}} \subseteq \llbracket \Gamma \rrbracket$ (and $\left|\llbracket \alpha \rrbracket_{\mathrm{F}} \cap \llbracket \Gamma \rrbracket\right| \geq 2$ ),

where $\llbracket \Gamma \rrbracket$ is the focus value of its coindexed antecedent.

If the second conjunct in gapping is taken to play a role parallel to congruent answers in Q/A sequences, and the first conjunct to play a role parallel to the preceding $w h$-question, it is immediately clear, that the condition stated in (25b) is not the subset-condition proposed by Rooth for Q/A sequences, but its inverse. Thus, a first step toward a uniform theory of short answers and gapping is the following condition:

(26) Uniform Condition for Short Answers and Gapping (first try)

In sentential answers and in non-initial conjuncts adjoin $\sim \Gamma$ to $\mathrm{CP}$. 
a. $\alpha \sim \Gamma$ presupposes that $\llbracket \alpha \rrbracket_{\mathrm{F}} \subseteq \llbracket \Gamma \rrbracket$

b. where $\Gamma$ picks up the denotation of its coindexed antecedent, if it is of type $\langle\langle s, t\rangle, t\rangle$; else it picks up the focus value of its coindexed antecedent.

If condition (26) is fulfilled, ellipsis in congruent answers and non-initial conjuncts is licensed.

\subsection{Short Answers, Gapping and 'Questions under Discussion'}

Though based on the same kind of constraint, this condition still appears to be to some extent arbitrary - the antecedents in short answers and in gapping are of a different nature, and it doesn't capture the intuition expressed in Steedman's quote. But how to do justice to this intuition? The basic idea is quite simple: suppose that - at least in principle- every utterance in discourse relates to an implicit or explicit $w h$-question (e.g. Roberts, 1996; Büring, 2003). Thus, if an utterance like (27b) is not explicitly linked to a wh-question, an implicit wh-question —a 'question under discussion' (QUD) — needs to be reconstructed on the basis of the focus/background structure carried by the first conjunct; if it is minimally focused, there is exactly one wh-question the utterance can be linked to - the question Who ate what? in case of (27b).

(27) a. [Who ate what? $]_{i}\left[\left[[\mathrm{JOHN}]_{\mathrm{F}}[\mathrm{BREAD}]_{\mathrm{F}}\right] \sim \Gamma_{i}\right]$, and $\ldots$

b. $[\mathrm{JOHN}]_{\mathrm{F}}$ ate $[\mathrm{BREAD}]_{\mathrm{F}}$, and $\left.\left[\left[[\mathrm{HARRY}]_{\mathrm{F}} \text { [BANANAS }\right]_{\mathrm{F}}\right] \sim \Gamma\right]$.

Having reconstructed the most salient QUD on the basis of the first conjunct, the second conjunct can then be taken to 'answer' this very question. Seen from the perspective of discourse structure, gapping thus can be reduced to the $\mathrm{Q} / \mathrm{A}$ relation: gapping is simply 'answering an implicit wh-question'.

But what about cases of wide focus in first conjuncts like, e.g., in (28)? In this case a complete set of possible QUDs -including e.g. What happened?, Who gave Sue what?, Who gave what to whom? etc.is reconstructed, from which the speaker chooses exactly one as the most salient QUD, and relative to which he utters the second and other non-initial conjuncts. This immediately accounts for the possibility of different continuations in case of gapping, see (28a) vs. (28b).

(28) a. [John gave Sue a BOOK $]_{F}$, and $[\text { BILL }]_{F}[\text { A BASEBALL }]_{F}$.

b. [John gave Sue a BOOK $]_{F}$, and $[\mathrm{BILL}]_{\mathrm{F}}[\mathrm{ANN}]_{\mathrm{F}}$

If this is correct, then we can state the following condition on short answers and gapping:

(29) Uniform Condition for Short Answers and Gapping (within alternative semantics) In short answers and in non-initial conjuncts adjoin $\sim \Gamma$ to $\mathrm{CP}$.

a. $\alpha \sim \Gamma$ presupposes that $\llbracket \alpha \rrbracket_{\mathrm{F}}=\llbracket \Gamma \rrbracket$,

b. where $\Gamma$ anaphorically relates to the most salient QUD.

Note that here semantic identity between $\Gamma$ and the focus value of $\alpha$ is required, for otherwise choosing a most salient QUD is not uniquely determined in case of wide focus in first conjuncts.

\subsection{The Case of Underfocusation}

Despite its elegance and generality, there is a non-trivial problem in this theory that leads to an, I think, interesting reformulation of this approach within Schwarzschild's (1999) theory of F-marking. Consider the German Q/A sequence in (30). The discourse preceding the question in (30) contextually restricts its denotation which is the set of propositions given in (31);

(30) [We know that both of you stole something. One stole a hand bag, the other one stole a DVD player. Now,] Was davon hast DU getan? ('What did YOU do?')

a. Ich habe [Die HANDtasche $]_{F}$ geklaut.

the hand bag $]_{F}$ stolen 
b. [Die HANDtasche] $]_{\mathrm{F}}$ [tatt.

* [the hand bag $]_{\mathrm{F}}$ ten

$$
\begin{aligned}
\llbracket(30) \rrbracket^{c} & =\{\text { that you stole a hand bag, that you stole a DVD player }\} \\
& =\llbracket \text { What did you steal? } \rrbracket^{c}
\end{aligned}
$$

this set of propositions is, however, identical to the denotation of the question What did you steal? uttered in the same context. Thus, it is wrongly predicted that the question in (30) can be answered with (30b). Note by the way that the same argument applies to Merchant's (2003) overt movement account, since (i) the semantic condition made use of in (29b) is stronger than e-Givenness (see above), and (ii) there is only one potential candidate for movement, namely the direct object.

In Reich (2002b, 2003) — basically following Drubig (1994) and Krifka (2001) — data like this have been taken to show that we need to assume that $w h$-questions denote structured propositions rather than unstructured ones. If we furthermore assume that interpreting minimal foci results in a set of structured propositions too, the anaphoric relation proposed in (29b) will induce the F-marking on the VP as required.

\section{An Alternative Analysis}

It seems, however, that there is an unstructured alternative to this approach within Schwarzschild's (1999) theory of F-marking and accent placement. Let's assume that in wh-questions all wh-phrases undergo LFmovement to SpecCP; then we can formulate a different anaphoric relation — see (32) — that makes the correct predictions, if $\gamma$ is coindexed with the question's IP (or the phase vP), and if —as has already been assumed-we allow this anaphoric relation to overrule AvoidF: the existential closure of the question's IP on LF (i.e., the question modulo (complex) wh-phrases) needs to entail the answer's F-closure.

$$
\alpha \sim \gamma \text { presupposes that } \operatorname{ExClo}(\llbracket \gamma \rrbracket) \text { entails } \operatorname{FClo}(\llbracket \alpha \rrbracket)
$$

(33) a. Was 1 ? [du hast $t_{1}$ getan $]_{i}$

b. [[teh habe $\left.\left.\left[[\text { Die HANDtasche }]_{\mathrm{F}} \text { geklaut }\right]_{\mathrm{F}}\right] \sim \gamma_{i}\right]$

The basic idea underlying the constraint in (32) is to somehow locally restrict salient antecedents for Givenness to the most salient QUD, but — and this is crucial for the distribution of accents - without at the same time completely excluding relevant previous context. Now, let's pose again the crucial question:

Is condition (32) an adequate condition for ellipsis in Q/A sequences?

No, of course it is not an adequate condition all by itself. But if we take into account that we need to impose an $\in$-condition on well-formed sentential answers anyway - to account for sortal restrictions, the interplay of both conditions does in fact result in an adequate semantic constraint on ellipsis:

(34) C-Answer: $\llbracket A \rrbracket \in \llbracket Q \rrbracket$. Accounts for

a. sortal restrictions imposed on well-formed answers by $w h$-phrase restrictions

b. semantic identity modulo (complex) wh-phrases

To sum up, we can state the following conditions on short answers and gapping:

(35) Uniform Condition for Short Answers and Gapping (within Schwarzschild, 1999)

In short answers and in non-initial conjuncts adjoin $\sim \gamma$ to $\mathrm{CP}$.

a. $\alpha \sim \gamma$ presupposes that $\operatorname{ExClo}(\llbracket \gamma \rrbracket)$ entails FClo $(\llbracket \alpha \rrbracket)$

b. $\quad \gamma$ anaphorically relates to IP (vP) of the most salient QUD.

The proposal in (35b) does indeed avoid recourse to structured propositions. There are two drawbacks though: first, this proposal presupposes an unstructured solution (see e.g. Reich, 2002a, for discussion); and second, it requires that in gapping the context variable $\gamma$ picks up part of an implicit [!] QUD; whether such LF-constituents are in fact accessible in D-trees has to be left open here for future research. 


\section{Some Implications of a Uniform Approach to Short Answers and Gapping}

In the last part of the paper, I want to point out some possible problems of a uniform approach to short answers and gapping, and some interesting implications for the structure of discourse.

Gapping in embedded contexts As example (36) below shows, gapping —in contrast to short answersalso occurs in embedded contexts; that this is not true of short answers in $\mathrm{Q} / \mathrm{A}$ sequences is probably simply due to the fact that both questions and answers necessarily carry illocutionary force.

(36) Ich glaube/weiß, dass Hans Anna eingeladen hat und Peter Maria.

I believe/know, that Hans Anna invited has and Peter Maria.

What is by far more interesting, however, is that (36) also shows that -if the uniform approach to short answers and gapping is correct - we need to assume that first conjuncts evoke a (set of) QUD(s) even if they occur in embedded contexts; this seems to be reasonable in light of the following example, where an embedded question without illocutionary force is nevertheless answered, if possible:

(37) Do you know, who won the lottery? Yes, Joe.

Gapping within short answers Essentially the same assumption will then account for the possibility of gapping within short answers, see e.g. (38):

(38) a. Was hast du gesagt? [What did you say?]

b. Dass Anna ein Buch bekommt und Peter ein Fahrrad bem. that Anna a book gets and Peter a bycicle

Locality II Short answers and gapped clauses also differ with respect to the possibility of separating them from their antecedent by another intervening potential antecedent: in gapping the result is definitely ungrammatical, see (39a); in case of short answers we can only observe that the hearer is uncertain whether the term is intended to answer the first question or whether it is intended to answer the second, see (39b).

(39) a. *Sue gave a book to Harry, Bill gave a ring to Sue, and Harry Bill.

b. Who gave a book to whom? (And) Who gave a ring to whom? Harry to Bill.

Ungrammaticality in (39a) can be accounted for straightforwardly: the second conjunct in (39a) introduces a new and different set of potentially most salient QUDs, and thus excludes linking to the first conjunct. This should predict that the short answer in (39b) can only be linked to the second question. To avoid this conclusion, we need to assume that in case of explicit questions an immediately following second question does not necessarily replace the previous QUD as the most salient QUD.

The tensed S-condition In Neijt (1979) an example is discussed, where the predicted parallelity between wh-questions and gapping seems to break down: although there are cases of 'long $w h$-movement' out of tensed clauses like, e.g., (40a), corresponding cases of 'long gapping' — see (40b) — are out.

(40) a. What did you tell her $t$ that you sent $t$ to Mary?

b. *Peter told her that he sent something to Mary, and John hal to Sue.

However, given that the uniform approach developed above is correct, the relevant QUD presupposed in (40b) is of course not (40a), but (41). At least in German, the corresponding wh-question is definitely out.

(41) Who told her that he sent something to whom?

(42) a. *Wer erzählte dir, dass er etwas wem geschickt hat?

b. *Peter erzählte dir, dass er etwas Hans geschickt hat und

Hans ezältir, Peter hickt hat. 
$P$-stranding Another potential problem for a uniform approach to short answers and gapping concerns English data related to P-stranding. In English we can observe that short answers show a strong tendency toward 'P-stranding' - see (43) and (44), whereas gapping behaves more or less parallel to the German short answer pattern — see (45) and (46).

(43) Mit wem hast du gesprochen? / Who did you talk to?

a. Mit meinem Nachbarn. / ?To my neighbour.

b. ?Meinem Nachbarn. / My neighbour.

(44) Über was habt ihr gesprochen? / What did you talk about?

a. Über Ethik in den Wissenschaften. / ??About ethics in science.

b. ?Ethik in den Wissenschaften. / Ethics in science.

(45) The men talked about the Red Sox, and

a. the women about ethics in science.

b. ?the women ethics in science.

(46) Bill talked to John's mother, and

a. Mary to Janet's mother.

b. ?Mary Janet's mother.

Here, the proposed alternatives make different predictions. Whereas the proposal based on Schwarzschild is sensitive to (LF) pied piping, and thus cannot account for the English gapping data, the version based on Rooth's alternative semantics is not sensitive to any kind of movement operations, and thus cannot account for the German data and the English gapping data without further assumptions.

\section{Summary}

In this paper I argued for and developed a uniform analysis of short answers and gapping. The basic idea underlying this analysis was that both short answers and gapped sentences should be taken as 'answering' the most salient 'question under discussion' (QUD), which is either explicitly given - in case of short answers - or which needs to be reconstructed on the basis of the focus/background structure of the first conjunct. Two variants of this analysis have been presented, one within Rooth's alternative semantics, one within Schwarzschild's theory on F-marking and accent placement. In the last part of the paper some potential problems and some interesting implications for the structure of discourse have been outlined.

\section{References}

Büring, Daniel (2002). Question-Answer Congruence - Unstructured: Comments on Krifka (2001). Ms., UCLA.

Büring, Daniel (2003). On D-Trees, Beans, and B-Accents. Linguistics and Philosophy 26, 511-545.

Drubig, Hans Bernhard (1994). Island Constraints and the Syntactic Nature of Focus and Association with Focus. Arbeitspapiere des Sonderforschungsbereichs 340, Nr. 51. Stuttgart/Tübingen.

Hankamer, Jorge (1979). Deletion in Coordinate Structures. New York: Garland Publishing.

Krifka, Manfred (2001). For a Structured Account of Questions and Answers. In: Audiatur Vox Sapientiae. A Festschrift for Arnim von Stechow. Berlin: Akademie Verlag. 287-319.

Merchant, Jason (2001). Sluicing, Islands, and the Theory of Ellipsis. Oxford: Oxford University Press.

Merchant, Jason (2003). Fragments and Ellipsis. Ms., University of Chicago.

Reich, Ingo (2002a). Pied Piping and the Syntax and Semantics of Complex wh-Phrases. In: Simon Mauck \& Jenny Mittelstaedt, eds., Georgetown University Working Papers in Theoretical Linguistics, Volume 2 (2002). Georgetown University. 263-286.

Reich, Ingo (2002b). Question/Answer Congruence and the Semantics of wh-Phrases. Theoretical Linguistics 28, 73-94.

Reich, Ingo (2003). Frage, Antwort und Fokus. Berlin: Akademie Verlag.

Roberts, Craige (1996). Information Structure in Discourse: Towards an Integrated Formal Theory of Pragmatics. In: J. Hak Yoon \& A. Kathol, eds., Ohio State University Working Papers in Linguistics 49. Ohio State University. 
Rooth, Mats (1992). A Theory of Focus Interpretation. Natural Language Semantics 1, 75-116.

Schwarzschild, Roger (1999). Givenness, AvoidF and Other Constraints on the Placement of Accent. Natural Language Semantics 7, 141-177.

Steedman, Mark (1990). Gapping as Constituent Coordination. Linguistics and Philosophy 13, 207-263. 


\title{
Proceedings of the 2004 Texas Linguistics Society Conference: Issues at the Semantics-Pragmatics Interface
}

\author{
edited by Pascal Denis, Eric McCready, \\ Alexis Palmer, and Brian Reese
}

Cascadilla Proceedings Project Somerville, MA 2006

\section{Copyright information}

Proceedings of the 2004 Texas Linguistics Society Conference: Issues at the Semantics-Pragmatics Interface (C) 2006 Cascadilla Proceedings Project, Somerville, MA. All rights reserved

ISBN 1-57473-417-2 library binding

A copyright notice for each paper is located at the bottom of the first page of the paper.

Reprints for course packs can be authorized by Cascadilla Proceedings Project.

\section{Ordering information}

Orders for the library binding edition are handled by Cascadilla Press.

To place an order, go to www.lingref.com or contact:

Cascadilla Press, P.O. Box 440355, Somerville, MA 02144, USA

phone: 1-617-776-2370, fax: 1-617-776-2271, e-mail: sales@ cascadilla.com

\section{Web access and citation information}

This entire proceedings can also be viewed on the web at www.lingref.com. Each paper has a unique document \# which can be added to citations to facilitate access. The document \# should not replace the full citation.

This paper can be cited as:

Reich, Ingo. 2006. Toward a Uniform Analysis of Short Answers and Gapping. In Proceedings of the 2004 Texas Linguistics Society Conference, ed. Pascal Denis et al., 69-78. Somerville, MA: Cascadilla Proceedings Project.

or:

Reich, Ingo. 2006. Toward a Uniform Analysis of Short Answers and Gapping. In Proceedings of the 2004 Texas Linguistics Society Conference, ed. Pascal Denis et al., 69-78. Somerville, MA: Cascadilla Proceedings Project. www.lingref.com, document \#1507. 